\title{
O Método Hermenêutico-Dialético aplicado às Ciências Sociais: uma análise sobre sua utilização para o estudo do tráfico de drogas
}

\author{
The Hermeneutic-Dialectic Method applied to Social Sciences: \\ an analysis of its use for the study of drug trafficking \\ ROBERTO MAgNO REIS NETTOOi 1 \\ Clay ANDERson Nunes Chagas $\mathbb{1}^{1}$ \\ ${ }^{1}$ Universidade Federal do Pará (UFPA), Belém, Pará, Brasil.
}

8003

RESUMO - O presente estudo teve como objetivo demonstrar aplicabilidade do método hermenêuticodialético como forma de interpretar e analisar a complexidade inerente ao fenômeno social, político, econômico e territorial denominado tráfico de drogas. Para tanto, perfez uma breve discussão a respeito dos métodos mais comuns no estudo do tema e suas respectivas limitações. Igualmente, explicou as principais linhas e procedimentos relativos ao método hermenêutico-dialético. Por fim, demonstrou como o método em questão pode representar, por sua postura de valorização da linguagem (sem olvidar variáveis que a influenciam no contexto do tempo-espaço), não só um procedimento coerente ao tratamento de questões complexas nas ciências sociais (com enfoque sobre o tráfico de drogas), mas, também, uma postura epistemológica que propicia uma autorreflexão dos próprios postulados do estudo e da postura científica de seus autores.

Palavras-chave: Método Hermenêutico-Dialético. Ciências Sociais. Tráfico de Drogas.

ABSTRACT - The objective of this study was to demonstrate the applicability of the hermeneutic-dialectical method as a way of interpreting and analyzing the complexity inherent in the social, political, economic and territorial phenomenon known as drug trafficking. To do so, Perfez a brief discussion about the most common methods in the study of the subject and its respective limitations. He also explained the main lines and procedures relating to the hermeneutic-dialectical method. Finally, it demonstrated how the method in question can represent, for its attitude of valuing language (without forget variables that influence it in the context of time-space), not only a coherent procedure for the treatment of complex issues in the social sciences (with focus on drug trafficking), but also a epistemological stance that provides a reflection of the study's postulates and the scientific posture of its authors.

Keywords: Hermeneutic-dialectical method. Social sciences. Drug trafficking. 


\section{Introdução}

C

onsiderando que o diferencial inerente ao conhecimento científico reside, justamente, em sua proposta de utilização da razão para interação, interpretação, modificação e aperfeiçoamento do senso comum - com a superação de seus não raros postulados fragmentários e, em muitos casos, preconceituosos (MATALLO JR., 2012) -, é certo que aquele não pode, de maneira alguma, prescindir de um método que o conduza. O método (do grego méthodos), por sua vez, pode ser compreendido como o caminho conducente a um determinado fim (MARTINS; THEÓPHILO, 2016), ou seja, o "procedimento adequado para estudar ou explicar um determinado problema[...]", ou "[...] o caminho que se deve percorrer [...]" (OLIVEIRA, 2014, p. 48) para atingir os objetivos de uma pesquisa.

Trata-se, portanto, do modo de abordar concepções a respeito de um ou mais fenômenos, numa transparente visão de como o pesquisador encara a realidade e os elementos contextuais que a compõem (MARTINS; THEOPHILO, 2016). Sua ideia, portanto, diz respeito à identificação do eixo filosófico/ epistemológico de um estudo (TEIXEIRA, 2011), necessário à coerente aplicação das abordagens, técnicas ou instrumentos de pesquisa e análise adotados.

Trata-se de uma questão de responsabilidade (OLSEN, 2015) e de honestidade intelectual (MEZAROBA; MONTEIRO, 2014), na medida em que expõe o substrato a partir do qual o pesquisador interpreta 0 mundo a seu redor. Além disso, representa uma verdadeira "teoria da investigação" (MARCONI; LAKATOS, 2016, p. 66) que sistematiza as etapas de apreensão do conhecimento concretizadas pelo autor de um estudo.

Compreender, no entanto, que o método representaria um conjunto de regras infalíveis no processo de apreensão do saber, decerto, seria um equívoco, uma vez que aquele estaria sempre em devir (MARTINS, THEÓPHILO, 2016): ele seria uma estratégia mais apropriada diante de um caso concreto, para superação das sombras que ocultariam as conclusões buscadas pelo pesquisador e que, ainda, deveria levar em conta sua própria experiência dentro do mundo científico.

Na medida em que o pesquisador mergulha nas águas do conhecimento que o cercam, enquanto ser humano, ele também se depara com o próprio drama de (re)construir sua própria identidade (BAUMAN, 1998) de acordo com os conhecimentos acumulados e as novas concepções que os saberes lhe fornecem sobre seu lugar e papel dentro da realidade. O cientista e suas visões, portanto, também são variáveis dos rumos de uma pesquisa (MINAYO, 2002).

Afinal, "a ciência e a tecnologia são boas e más também em razão de que, uma vez subvertidas por interesses econômicos e políticos, não podem mais ser livres de valores (value free) - se é que algum dia o tenham sido" (MORAIS, 2012, p. 108). Ou seja, as ciências (e os cientistas), a despeito do mito da neutralidade científica, sempre deixarão transparecer, nas entrelinhas de suas proposições e teorias (isentas ou não de influências), sua forma de conceber e interagir com o mundo (ALVES, 2013; OLSEN, 2015).

Expor o método, repita-se, é uma questão de honestidade e autorreflexão. E, diante de uma sociedade plural, é natural que se observe a existência de uma pluralidade de métodos ditos convencionais e de outros ditos não convencionais (MARTINS; THEÓPHILO, 2016), conforme o posicionamento de cada cientista ou grupo de pesquisadores a respeito da realidade e da própria ciência.

A partir da compreensão desta ideia de liberdade cognitiva, tem-se observado um novo fôlego relativo a posturas interdisciplinares ou multidisciplinares neste primeiro quartil do Século XXI, sobretudo, em função da necessidade de análises mais amplas e multifocais em torno de fenômenos complexos que exsurgem (BICALHO; OLIVEIRA, 2011), propugnando-se, assim, o uso de métodos mistos como altamente viáveis e desejáveis (OLSEN, 2015).

Contudo, é importante a reflexão prévia a respeito da potencialidade do uso de cada método (e técnicas de pesquisa e análise que o compõe) a certos objetos de estudo, tomando por base as características e complexidades inerentes a estes últimos. Isso, justamente, para não incorrer no velho problema de afirmação de verdades parciais e blindadas por recortes seletivos de uma realidade (FEYERABEND, 2011), numa mostra de pseudociência (ALVES, 2012). 
Neste contexto, o presente estudo pretendeu demonstrar aplicabilidade do método hermenêuticodialético (MINAYO, 2002) como forma de interpretar e analisar a complexidade inerente ao fenômeno social, político, econômico e territorial caracterizado como tráfico de drogas, de modo a fornecer um possível substrato teórico consistente para compreensão e análise de resultados de posteriores pesquisas que o elenquem como objeto. Dessa forma, consubstanciou, é de se dizer, uma opção teórica tomada como primeiro passo para estudo daquele fenômeno, em pesquisa desenvolvida pelos autores dentro da linha de pesquisa em Conflitos, Criminalidade e Tecnologia da informação, do Mestrado em Segurança Pública da Universidade Federal do Pará.

A complexidade inerente ao fenômeno, aliás, se coloca desde a discussão que envolve sua conceituação: embora o termo se origine de uma política de Estado (a lei), de natureza jurídico-penal proibitiva (CARVALHO, 2016), a noção de tráfico de drogas se encontra historicamente definida por fatores políticos e econômicos voltados a consagração de interesses ligados à indústria e à balança comercial, assim como, a um discurso médico-jurídico, que, no fundo, em nada se identifica com a reputada proteção da saúde da população (RODRIGUES, 2004; ARAÚJO, 2012).

De igual maneira, tem-se que o tráfico detém múltiplas realidades analíticas, cada uma, detentora de uma visão diferente sobre o mesmo fenômeno: a realidade dos órgãos oficiais, que o compreendem sob a visão hegemônica de um inimigo a ser combatido, sob o discurso de guerra às drogas (RODRIGUES, 2004; D'ÉLIA FILHO, 2014); a realidade dos sujeitos envolvidos com práticas criminosas e suas construções simbólicas, linguísticas e identitárias (MARQUES, 2014); a realidade da população que, sem um maior aprofundamento sobre a questão, tem sua opinião diretamente influenciada por ações externas, sobretudo, midiáticas (D'ÉLIA FILHO, 2014) etc.

Sobretudo, deve-se destacar que a aplicação prática da política antidrogas, em verdade, revela uma atuação seletiva - e, em muito, preconceituosa - que, comprovadamente, atinge de maneira significativa camadas pobres e estigmatizadas da população (RORIGUES, 2004; D'ÉLIA FILHO, 2014), a despeito de o tráfico ser presente em todo e qualquer extrato social. Por estes motivos, especialmente, este estudo depende de uma visão científica tão pluralista quanto o mesmo, de modo a buscar, rigorosamente, transparência e objetividade quanto aos resultados de investigações que o envolvam (MEZAROBA; MONTEIRO, 2014; OLSEN, 2015).

Desta feita, o presente ensaio, que se ateve ao campo epistemológico, ou seja, do estudo das ciências (MARTINS; THEÓPHILO, 2016), se justificou, além do acréscimo aos debates metodológicos, por oferecer uma alternativa interpretativa não só ao estudo do fenômeno acima proposto, como, de diversos outros ínsitos à área das ciências sociais (sem, obviamente, negar a importância ou aplicabilidade de todos os demais métodos, tradicionais ou não). Por conseguinte, revelou um possível procedimento investigativo apto a originar conclusões plurais, diante da complexidade humana e suas manifestações racionais, culturais, etc. E, por fim, revelou também componentes que, postos em prática, podem incentivar a já referida transformação do ser-cientista a partir da experiência concreta vivenciada por ele (BAUMAN, 1998).

Afinal, negar as limitações das práticas científicas, certamente, importaria negar todas as barreiras ideológicas travestidas de ciência. E, esta postura, por sua vez, ao invés de fortalecer a produção do conhecimento, apenas criaria hipóteses ad hoc (improvisadas) que ocultariam lacunas e defeitos, em defesa parciais e, muitas vezes, interessantes somente a determinados grupos, em prejuízo da sociedade a qual se dirige o labor científico (FEYERABEND, 2011).

Pela interdisciplinaridade do método, propôs-se a maturidade de superar os obstáculos científicos a partir de uma análise do objeto, paralela a uma autoanálise do pesquisador e do tempo-espaço em que os mesmos se inserem.

Ademais, deve-se salientar que o estudo se subdividiu em três subseções de desenvolvimento: a primeira, que discutiu as abordagens utilizadas para estudo do tráfico de drogas no Brasil e as críticas que Ihes são opostas; uma segunda, que abordou as principais linhas do método hermenêutico-dialético; e, uma terceira que discutiu a aplicabilidade deste método ao estudo do fenômeno nominado tráfico de drogas, revelando suas potencialidades e limitações. 


\section{Dos métodos mais comuns no estudo do tráfico de drogas e das críticas relativas a sua utilização}

Como é natural se esperar da complexidade inerente ao fenômeno social classificado como tráfico de drogas, também, mostrou-se bastante diversificado o uso de diferentes métodos para o seu estudo e compreensão. Análises jornalísticas como as de Amorim (2011; 2013) e Saviano (2014), por exemplo, são bastante comuns, a despeito da não adoção explícita de um método de condução do estudo (o que, é de se dizer, não macula a verossimilhança das informações apresentadas, diante da profundidade das pesquisas empíricas realizadas pelos autores - certamente, mais subsistentes que muitos textos ditos científicos à disposição da comunidade).

Por conseguinte, a adoção do método histórico-dialético - como, por exemplo, no estudo de Rocha (2010) - ou de variantes daquele método - como o uso da criminologia crítica por Anitua (2015), D'élia Filho (2014) e Carvalho (2016), e, ainda, a postura genealógica adotada por Rodrigues (2004) - também se denotaram relevantes contribuições metodológicas para este estudo, sobretudo, por terem especial foco em revelar as dissimetrias, simulacros e conflitos de poder inerentes aos sujeitos sociais.

No entanto, como crítica àquela postura científica, pode-se apor a tradicional compreensão de que a oposição de classes e interesses antagônicos não é suficiente para total explicação do tráfico, enquanto fenômeno social. Afinal, as próprias organizações do comércio de drogas, em seu meio, reproduzem práticas de estratificação social comuns do capitalismo moderno (PICANÇO; LOPES, 2016) impondo uma visão científica que deve ir além da dicotomia opressores versus oprimidos, e, de detentores de meios econômicos versus explorados, muitas vezes encerradas por algumas análises críticas-dialéticas.

A própria realidade dicotômica que engloba, paralelamente, oligopólios transnacionais e pequenos traficantes (D'ÉLIA FILHO, 2014; RODRIGUES, 2004), aliás, confirma a verossimilhança desta afirmação: potenciais explorados/oprimidos podem, dependendo do contexto, figurar como exploradores/ opressores. Igualmente, pode-se constatar que as entidades e agentes do tráfico podem figurar ao mesmo tempo, e, sem maiores problemas, na qualidade de estrutura e superestrutura social, o que traz certos problemas interpretativos a postulados propugnados nalguns estudos que se valem daquele método.

Por conseguinte, como aponta Rocha (2010), constata-se que inúmeros textos não mencionam claramente o método utilizado nas pesquisas, embora o caráter qualitativo das análises induza a uma opção aparentemente fenomenológica. Constatou-se também o uso da fenomenologia em estudos de campo, como os desenvolvidos por Fromm (2014) e Garcia (2012), que buscaram, através de um esforço interpretativo da razão comunicativa dos sujeitos pesquisados, revelar a realidade do tráfico de drogas, imagens e simbologias que recaiam sobre o ele.

Alguns estudos, inclusive, realizaram verdadeiras etnografias a respeito do tráfico - como os desenvolvidos por Zaluar (1994; 2004), por exemplo -, firmando investigações que, muito além da comunicação, acabaram por desvelar questões culturais a respeito do tráfico em simbiose com a comunidade em que se encontrava inserido. Como crítica a estas posturas, primeiramente, tem-se que o uso das categorias empíricas como elemento-chave de interpretação, decerto, pode ignorar a existência de relações dissimétricas entre os diversos seres humanos envolvidos nesse mundo, assim como, entre eles e os representantes de órgãos estatais, que, em sua comunicação, se utilizam categorias iguais, porém, sob significados diversificados e desvinculados em sentido entre si.

É bastante emblemático, nesse sentido, o exemplo destacado por Marques (2014), que identificou que o termo crime detinha significado de movimento no contexto de organizações criminosas e comunidades encarceradas, diferindo totalmente do conceito jurídico-positivo utilizado pelos órgãos estatais (relativo à transgressão de uma norma penal). Assim, a própria linguagem se mostrou determinada pelo tempo-espaço, bem como, nível social das interações humanas, e, ainda, pelas estratégias de resistência e sobrevivência usadas pelos atores sociais.

É comum perceber, desta forma, categorias iguais e significantes absolutamente diferentes, num mesmo tempo-espaço, o que, obviamente, acabou sendo analisado somente de maneira superficial por 
alguns estudos. A mesma crítica, inclusive, pode ser apontada em relação a estudos etnográficos, cujos elementos culturais acabam por revelar apenas a ideia de cultura do tráfico ou suas formas em um único substrato cultural, às vezes, equivocadamente universalizado.

Ademais, é comum constatar, principalmente em estudos mais superficiais a respeito do tráfico, a utilização de métodos indutivos, dedutivos e hipotético-dedutivos. Esta postura científica mais conservadora, por outro lado, acabava, mais cedo ou mais tarde, por buscar embasamento em pesquisas pautadas nas demais metodologias citadas, ou, ainda, numa perigosa postura eclética pautada em teóricos com diferentes visões de mundo incompatíveis.

Obviamente, quaisquer dos métodos podem sanar as problemáticas acima, se executados com cuidado e preciosismo pelo autor da pesquisa. Porém, ainda assim, o modus operandi de cada uma exigirá um esforço redobrado do cientista para compreender as lacunas do próprio procedimento e, assim, trabalha-las fora de hipóteses improvisadas ou de pressuposições metafísicas (FEYERABEND, 2011).

O grande desafio de se estudar o tráfico de drogas, portanto, reside na necessidade de conformação de um método que compreenda as representações sociais e identitárias, materializadas a partir da razão de cada um dos atores sociais envolvidos (MARTINS; THEÓPHILO, 2016) - numa clara abordagem empírica -, que, no entanto, não olvide que as manifestações pragmáticas ou racionais da cultura e comunicação se circunscrevem a um contexto histórico e espacial, bem como, são condicionadas por relações de poder e escalas de estratificação social - conforme advertido pela visão histórico-dialética (MARTINS; THEÓPHILO, 2016) - que precisam ser desveladas para a perfeita compreensão do objeto.

Noutras palavras, compreender o tráfico depende de uma postura científica pautada, de fato, numa análise empírico-analítica, mas que, ao mesmo tempo, se revele subsistentemente crítica à representação humana da realidade. Daí a proposta de utilização do método hermenêutico-dialético, em função das potencialidades que o mesmo propiciaria ao estudo daquele fenômeno, conforme as características expostas na seção seguinte.

\section{Do método Hermenêutico e Dialético}

Propugnado a partir de interpretações dos estudos desenvolvidos por Habermas (1987) em crítica à teoria do agir comunicativo (MINAYO, 1994) e ao modelo hermenêutico desenvolvido por Gadamer (GONZALES, 1987), o método hermenêutico-dialético se propôs à categorização e interpretação de dados empíricos. Para isso, teve por base uma perspectiva transdisciplinar que conglobasse o mundo dos sentidos e das relações de poder.

O ponto de partida da compreensão hermenêutico-dialética, assim, foi a linguagem (MINAYO, 2002). Como afirmou Gonzalez (1987), a linguagem se encontraria na base da atuação do ser no mundo, conforme condições e convenções operacionalizadas e, ao mesmo tempo, limitadas por ela.

Assim, toda manifestação (ou produção) do conhecimento seria concebida a partir de conjuntos de símbolos (não adstritos à fala ou escrita, mas a toda e qualquer simbologia capaz de trazer significados compreensíveis, como números, códigos, mapas, organogramas etc. (MINAYO, 2002)) que, uma vez interpretados por intermédio da razão, permitiriam a compreensão humana sobre um fenômeno ou mensagem (GONZALEZ, 1987).

Segundo Minayo (2002), foi com esta aproximação entre a visão hermenêutica e a fenomenologia (como forma de interpretar fenômenos sociais a partir dos significados - e simbologias - assumidos no âmbito da razão humana (MARTINS; THEÓPHILO, 2016) que se passou a entender que a objetividade da análise hermenêutica (o significado) estava relacionada às condições de vida do ser que agia por meio da comunicação (a intencionalidade).

Noutras palavras, constatou-se que uma análise pretensamente objetiva dos significados da linguagem, perpassaria por condições subjetivas, que, por sua vez, estariam diretamente vinculadas à qualidade da (sobre)vivência do interlocutor num tempo-espaço determinados. Objetividade e subjetividade, nesta senda, se tornariam elementos inseparáveis. 
Desta maneira, o que aparentemente se denotaria como uma verdade capaz de ser abstraída da análise hermenêutica, por outro lado, poderia ocultar uma falsa consciência da realidade, legitimadora de relações de exploração sistematicamente organizadas (GONZALES, 1987). Descobriu-se, então, o que Habermas (1987) denominou de comunicação sistematicamente perturbada, ou seja, uma comunicação surgida no contexto de uma sociedade em que se admite a linguagem humana como alienável, ideologicamente influenciável, por estruturas de poder que lhe privariam de liberdades preliminares.

Inaugurou-se, assim, além de uma negação à universalidade hermenêutica (STEIN, 1983), a necessidade de se aliar o esforço interpretativo hermenêutico a uma crítica social que desvelasse o contexto de alienação em que a linguagem se encontrava, através do estranhamento e negação da informação fracassada em sua transparência (MINAYO, 2002).

Minayo (2002), indo além, asseverou ainda que o próprio pesquisador seria um sujeito inserido num dado contexto tempo-espaço, e, nessa qualidade, também condicionado por relações desiguais de poder e pré-juízos que influenciariam sua análise. Dessa forma, derrubando, portanto, o mito em torno da observação científica imparcial, o que, certamente, passou a exigir um cuidado redobrado por parte dos pesquisadores de qualquer estudo.

Em suma, o método questionou o tecnicismo inerente às posturas científicas meramente empiristas, condicionando um contexto histórico às simbologias da linguagem; propugnou a adoção de uma postura de autoconhecimento do pesquisador - como sujeito inserido num contexto espaço-temporal e invariavelmente interessado/influenciado pelo objeto de pesquisa; e, finalmente, incentivou a adoção de uma postura de superação das próprias visões parciais de um fenômeno (MINAYO, 2002), na busca de conclusões coerentes. $O$ método hermenêutico-dialético, portanto, muito além de uma forma de investigação científica, representou, segundo Stein (1983), uma postura filosófica e epistemológica de perceber e compreender, através da razão, a realidade posta aos olhos.

Em termos científico-metodológicos, por sua vez, Minayo (2002) sugeriu que a construção hermenêutico-dialética impenderia de alguns cuidados e posturas, o quais poderiam ser consolidados da seguinte forma: a) deve-se realizar uma análise dos aspectos históricos e conjunturais vinculados às fontes de pesquisa; b) é imperioso preservar um respeito pela racionalidade (por mais superficial que seja) de fontes empíricas, documentais e/ou bibliográficas analisadas, para ampla compreensão espaço-temporal do conhecimento produzido; c) deve-se buscar o sentido (intenção) do emissor das mensagens (quaisquer que sejam suas origens), ao invés de se crer numa verdade essencialista pré-formulada, colocando-se numa posição de abertura a outras visões de mundo (além da sua).

Em termos de potencialidades, o método em questão, ainda segundo Minayo (2002), propiciaria uma atitude crítica em relação aos dados empíricos, respeitando-se o aspecto histórico e espacial vinculado ao conhecimento produzido. Ainda assim, de acordo com o autor, buscando a superação das visões parciais e seletivas da realidade, num pluralismo metodológico apto a desvelar fenômenos complexos, através do casamento de técnicas qualitativas e quantitativas.

Ainda, como maneira de afastar a parcialidade autoral, Minayo (2005) propôs a realização de uma atividade de triangulação de métodos e dados, que pode ser alcançada tanto por intermédio de avaliações consecutivas do conhecimento produzido mediante o auxílio de outros pesquisadores, quanto pela comparação dos achados com outras teorias e estudos já desenvolvidos em torno da temática analisada. O objetivo, justamente, seria garantir a pluralidade de visões sobre um fenômeno, para desvelar (negação) uma verdade alienada por conjunturas sociais, revelando, ao fim, resultados mais próximos da realidade (síntese).

Conforme Gomes et al (2005), após uma primeira etapa de coleta de dados, seguida de uma segunda etapa, de categorização de dados analisados, seria nessa terceira etapa (de triangulação) que se buscaria a síntese dialética, por meio de uma reinterpretação dos achados voltada à compreensão dos conflitos inerentes ao processo interpretativo. Essa fase, por sua vez, seria marcada pela: a) comparação entre as teorias que já promoveram análise de dados empíricos semelhantes; b) análise dos textos com base nos contextos em que eles foram produzidos, com a devida crítica de situações histórico-espaciais influentes; 
e, c) avaliação comparativa entre os pressupostos do estudo (teoria base) e os dados empíricos colhidos (GOMES et al., 2005).

Com esta triangulação, se perfaria uma crítica à primeira visão geral obtida pelo autor (após coleta de dados), e, ao mesmo tempo, uma autocrítica sobre suas pressuposições (anteriores ao próprio estudo), de modo a negar e sintetizar (movimento dialético), em face da história e de outros saberes, os pré-conceitos que embasariam a pesquisa. O cientista, portanto, se tornaria um crítico da realidade e de si mesmo. Dessa maneira, enquanto a hermenêutica realizaria a busca por aparentes consensos linguísticos num tempoespaço determinado pelo estudo, a dialética orientaria o estudo em direção a uma atividade de negação e crítica, tanto dos resultados obtidos, quanto, sobretudo, da compreensão do próprio autor (ALENCAR; NASCIMENTO; ALENCAR, 2012). Seriam derrubados, assim, mitos objetivos e subjetivos no processo de pesquisa.

\section{Sobre a Hermenêutica-Dialética e sua aplicabilidade no estudo das Ciências Sociais e do fenômeno nominado tráfico de drogas}

O estudo em ciências sociais sempre se mostrou, por sua natureza, complexo. De acordo com Martins e Theóphilo (2016, p. 2), "O homem é um ser demasiadamente complexo para ser reduzido ao estado de objeto. O homem não pode ser observado sem ser influenciado e não pode ser isolado de seu contexto sem perder sentido e coerência", razão pela qual há quem até negue cientificidade às ciências sociais em razão dos naturais problemas de testagem e verificação de hipóteses relativas ao humano, como informou Feyerabend (2011).

E, essas limitações atingem níveis mais problemáticos ainda quando da pesquisa relativa a temas espinhosos, como é o caso típico dos estudos em segurança pública. O fato é que a ciência não pode fechar os olhos aos desafios de pesquisa oriundos de searas sociais, importante campo de necessário desenvolvimento à humanidade, donde substanciais questões brotam incessantemente, desafiando a estabilidade de comunidades e de estruturas sociais e orgânicas.

Conforme afirmaram Somekh et al. (2015), a pesquisa social, marcada pela imprevisibilidade do comportamento humano, depende de teorias e métodos que levem sua natural complexidade em conta, exigindo, portanto, um desenvolvimento epistemológico voltado a esta realidade. E, especialmente, considerando o potencial objeto de estudo denominado tráfico de drogas - como visto, bastante complexo -, é que esta afirmativa se torna mais válida ainda (ROCHA, 2010).

Diante disto, e, nos termos eleitos pelo objetivo central, surgiu a proposta de demonstrar a aplicabilidade do método hermenêutico-dialético à pesquisa social, como alternativa de análise a objetos complexos (o tráfico de drogas, em especial), questão da qual o trabalho se ocupou nesta seção.

Primeiramente, deve-se recordar que, conforme propugnou Minayo (2002), o método analisado se predispõe: a) análise de aspectos espaço-temporais; b) respeito à racionalidade das fontes; c) busca pela intencionalidade (sem olvidar as perturbações sistêmicas). Logo, essa seria uma proposta preliminar de análise do fenômeno ora eleito.

O estudo sobre o tráfico, assim, teria (ou deveria ter) início a partir de uma reconstrução histórica do conhecimento já produzido em torno do tema, o que, diga-se de passagem, é de considerável importância dentro de qualquer pesquisa que o tome como objeto. Não se trata simplesmente de realizar, afirme-se, uma análise exaustiva sobre o objeto de trabalho: a literatura brasileira e estrangeira é extremamente vasta em torno do assunto. Trata-se de estabelecer um recorte espaço-temporal coerente à compreensão do status do conhecimento relevante ao objeto de estudo.

Afinal, o consumo de substâncias capazes de alterar a normalidade dos sentidos é um fato presente ao longo da história humana (ARAÚJO, 2012). O que se mostra em franca contradição ao discurso das políticas proibitivas, nascidas a partir de interesses políticos e econômicos de certos grupos sociais, e, ideologicamente disfarçados por um discurso médico-jurídico (de defesa sanitária) e de guerra às drogas (RODRIGUES, 2004; CARVALHO, 2016). 
As políticas estatais, nesta perspectiva, acabaram por ocasionar a aplicação de uma legislação que, em momento algum, se preocupou em definir de maneira profunda e reflexiva o que seria realmente o tráfico de drogas (CARVALHO, 2016). E, com isso, ignorando seu caráter comercial e intrinsecamente ligado às lógicas de oferta/demanda do mercado, assim como, sua estratificação em grandes oligopólios (de agenciadores e produtores, atravessadores, grandes comerciantes, membros de grupos logísticos, etc.) e pequenos acionistas (pequenos produtores locais, revendedores de pequeno porte, dentre outros) ( $D^{\prime}$ ÉLIA FILHO, 2014). Tal contexto redundou em ações seletivas que, pragmaticamente, enfrentaram o problema apenas de maneira superficial: como se vê da prática jurídica, somente as parcelas e áreas mais vulneráveis e estigmatizadas da população foram atingidas pelas políticas de repressão, sem qualquer contrapartida social (D'ÉLIA FILHO, 2014), ao passo que o problema da produção, comércio e consumo em nada foi diminuído ou solucionado (UNITED NATIONS OFFICE ON DRUGS AND CRIME - UNODC, 2015), sobretudo, pela relativa intangibilidade dos grandes comerciantes e produtores (RODRIGUES, 2004).

A segregação social gerada por esta política repressiva, por sua vez, ocasionou a gênese de diferentes visões de mundo apreensíveis pela ciência social: a dos órgãos oficiais, dirigidos por um discurso oficial jurídico-legal de repressão às drogas (CARVALHO, 2016); outra, de mercado, utilizada de maneira extremamente eficiente pelos grandes oligopólios do tráfico num âmbito transnacional (SAVIANO, 2011); e, ainda, uma realidade inerente aos pequenos investidores no mercado da droga, mais suscetíveis de atingimento pelas políticas de repressão e por medidas de segregação (D'ÉLIA FILHO). E, nessa qualidade, acabam por desenvolver meios cada vez mais complexos de resistência, o que resultou, no Brasil do Século XX, no surgimento de complexas organizações criminosas (AMORIM, 2011; 2013).

Em linhas mais diretas, neste início de Século XXI, o tráfico se apresenta (como outros objetos suscitáveis, nas ciências sociais (BAUMAN, 2001)), como um problema transnacional enfrentado com políticas meramente locais. Dessa forma, a escolha pelo método em questão permite, num primeiro momento, a seleção de dados históricos-espaciais mais adequados ao contexto de estudo, obviamente, sem divorciá-lo de suas respectivas variáveis locais e globais. Exemplos interessantes podem ser encontrados em algumas obras, como se mencionou a seguir.

Silva, Pereira e Penna (2018), em estudo que teve como objeto a questão do Estereótipos de gênero no cuidado psicossocial das usuárias de cocaína e crack, obtiveram categorias de análise relevantes (como gênero, família, cuidado, fragilidade, etc.), a partir da interpretação da literatura preexistente, as quais, no dizer das autoras, permitiram sanar incompletudes que surgiriam da simples análise das falas.

Bortolozzi (2014), por sua vez, obteve do recorte histórico-espacial literário, importantes dados que permitiram a interpretação do papel da droga enquanto mercado de trabalho nas grandes cidades, de modo a compreender como crianças e adolescentes seriam atingidos e influenciados pelas relações travadas nesta economia ilegal.

Ainda, observa-se o estudo desenvolvido por Reis Netto e Chagas (2018b), onde o uso da literatura brasileira e estrangeira recente, sobre as relações entre tráfico de drogas e cárcere, permitiram a aproximação da práxis, ou seja, das estratégias e mecanismos utilizados por criminosos para integração do cárcere às redes territoriais externas da atividade.

Aliás, com base neste exemplo, observa-se também que, sob uma compreensão histórica-espacial, o método hermenêutico-dialético propiciou, também, um considerável trunfo relativo à análise de dados prévios relativos ao tráfico: a congregação compreensiva de múltiplas realidades linguísticas (a priori, iguais), permitindo sua realística inferência de acordo com o contexto social originário.

Explique-se: diante das variadas realidades produzidas no contexto do tráfico de drogas - marcadas por conflitos políticos, sociais e econômicos - foi natural, também, o surgimento de simbologias próprias a cada grupo de sujeitos envolvidos com aquele fenômeno, variáveis, ainda, conforme o território levado em conta em cada estudo (o âmbito dos órgãos de segurança, o âmbito dos órgãos médicos e sanitários, o âmbito dos órgãos educacionais, o âmbito de organizações criminosas ligadas à classes altas ou médias, o âmbito das organizações criminosas vinculadas à áreas mais pobres - como favelas e baixadas, o âmbito dos traficantes que trabalham no contexto do cárcere, etc.) e o nível socioeconômico e educacional dos atores (ou agentes) envolvidos. Enquanto método que propõe a interpretação desses saberes, o método 
hermenêutico-dialético permite uma análise conjunta de significantes que, a princípio, seriam totalmente diferentes, permitindo uma maior apreensão da realidade.

O respeito à racionalidade de cada uma destas fontes, portanto, se impõe como movimento fundamental à compreensão deste objeto de estudo. Afinal, ignorar esta complexidade linguística poderia importar numa incorreta interpretação de construções sociais diversas da lógica estatal-oficial (ainda preponderante), como, por exemplo, ocorre em relação aos mecanismos de julgamento realizados nos debates das organizações criminosas, que, embora sejam comparáveis a verdadeiros julgamentos, detém normas muito voláteis e flexíveis, bem como, compreensões de igualdade totalmente alheias àquelas estabelecidas pela legislação nacional (MARQUES, 2014).

Nesse sentido, toma-se como exemplos da diversidade linguística e necessidade de cuidadosa interpretação: a) o conceito de crime, que, na lógica oficial revela uma conduta tipificada (proibida), mas que, sob a lógica linguística do cárcere, se coloca como um movimento, algo do que se faz parte (MARQUES, 2014); b) o conceito de proceder, que, sob a lógica oficial remete a ideia de ritos ou processos, no contexto das faç̧ões criminosas, por sua vez, revela um código informal de condutas, necessário à convivência entre os irmãos (MARQUES, 2014); o significado de dar a volta, que revela um movimento corporal, na linguagem comum ou corriqueira, adquire uma conotação de traição ou de enganar nos negócios, nas relações de poder havida no mundo do tráfico (AMORIM, 2011, 2013).

O mesmo, ainda, se diga sobre pesquisas documentais que levem em conta de dados oficiais (fontes muito comuns no estudo do tráfico de drogas) que, normalmente, se atém a uma linguagem/conhecimento produzido conforme parâmetros técnico-jurídicos, ignorando, ao passo, simbolismos diferenciados, inerentes aos demais grupos sociais. Embora não se ignore a importância dos dados oficiais, sua construção revela apenas uma visão dentro do complexo contexto social, sendo importante sua comparação (triangulação) crítica com outros olhares.

Dessa forma, pode-se apreender (como ocorre na realidade prática das pesquisas sociais) que um símbolo (ou, ainda, a visão sobre um objeto ou fenômeno) pode ter variados significados, conforme o contexto social, sem variar, no entanto, o significante. É possível constatar, diante disso, que esta consideração do contexto espaço-temporal do fenômeno, aliada ao respeito pela racionalidade das fontes linguísticas de dados, certamente, rogaria, também, uma terceira atividade: a realização de uma comparação entre os dados teóricos e empíricos, capaz de desvelar as inevitáveis dissimetrias inerentes às relações de poder que, como dito, perturbariam aquela linguagem constatada junto às fontes de pesquisa.

Daí a importância da atividade triangulação de dados e teorias (MINAYO, 2002), consistente na comparação da teoria previamente formulada com dados coletados à luz de outros estudos e seus postulados (movimento dialético). Não se trata somente de negar o conhecimento corrente (o que tem levado alguns autores à uma defesa, pouco refletida, de uma desmedida legalização de entorpecentes, por exemplo), mas sim, de amadurecer as ideias trabalhadas em relação ao fenômeno, e, então, comparar as hipóteses levantadas com a opinião de outros autores e achados de outros estudos. Com isso, permitir-se-ia, além do alcance de uma pluralidade de visões sobre um dado fenômeno, a própria confrontação dos resultados de uma pesquisa corrente com os de outras análises, confirmando ou negando as conclusões de quaisquer deles, num afastamento de hipóteses improvisadas que, como já dito, somente atrapalham o desenvolvimento científico (FEYERABEND, 2011).

É importante ressaltar que, é justamente neste ponto, que surgiriam possíveis problemas relativos ao método em questão: a) a triangulação sempre deve tomar por base momentos e contextos históricos semelhantes, a não ser que se busque revelar dissonâncias ou dissimetrias de diferentes momentos temporais (o que deve ser expressamente manifestado pelo autor do estudo); b) a triangulação pressupõe a maturidade de se promover uma comparação de achados, perante teóricos, pesquisadores e dados de opinião e conteúdo diferentes daqueles de manifesta preferência do autor, sob pena de nada adiantar em relação à construção da verdade e afastamento de hipóteses improvisadas; e, c) a triangulação deve ser realizada sob um propósito dialético de questionar o real encontrado num estudo, por mais doloroso e frustrante que isto seja ao trabalho do pesquisador. 
A título de exemplo, foi pela triangulação entre falas de profissionais de saúde, a literatura e dados colhidos por meio de observação direta das ações, que permitiu que Silva, Pereira e Penna (2018) constatassem a existência de relações de poder, a partir de uma perspectiva de gênero, imposta pela visão de mundo dos atendentes, que condicionaram suas ações quanto ao tratamento de usuárias de crack.

Igualmente, foi pela atividade de triangulação que Reis Netto e Chagas (2018b) constataram que o comércio de drogas dentro do cárcere, revelava que a droga, muito além de um produto disponível no mercado ilegal, representava um instrumento de poder às facções criminosas, que permitia o controle dos faccionados, por meio da oferta/demanda de entorpecentes, conforme interesses das primeiras.

Mais adiante, em outro estudo, os mesmos autores utilizaram a atividade de triangulação de dados literários e empíricos (colhidos em entrevistas com agentes da segurança pública) realizando uma atividade de verificação das informações literárias à luz da realidade local, inclusive, encontrando questões divergentes das apontadas na literatura (como, por exemplo, em relação à dinâmica das facções criminosas e comércio de drogas na base estudada) e questões sem referência literária anterior (a respeito de relações entre o tráfico e a comunidade, bem como, sobre a inércia política em torno dos problemas apontados) (REIS NETTO; CHAGAS, 2018a).

Em todos os exemplos, portanto, constata-se o advento de conclusões que certamente não seriam alcançadas por meio de uma visão isolada ou meramente descritiva dos dados colhidos pelos pesquisadores, mas que foram reveladas a partir de uma ampla triangulação entre o empírico e o teórico. Assim, sob a construção, reanálise e reconstrução de dados, o método hermenêutico-dialético se denota bastante apropriado ao estudo das ciências sociais, conforme sugerido por Stein (1983), Gonzales (1987) e Minayo (2002), em especial, para o estudo de objetos sociais complexos (como o tráfico de drogas, nos termos acima discutidos).

É claro que, neste caso, esta proposta transdisciplinar não foi apresentada como um método infalível ou proposta irrecusável. Afinal, como manifestado nas linhas iniciais, a adoção de qualquer método muito tem a ver com as (inafastáveis) preferências e subjetividades do próprio pesquisador, de acordo com os contornos de sua visão de mundo (MORAIS, 2012).

Porém, é de se afirmar que sua maior potencialidade reside justamente neste ponto: a hermenêuticadialética não se propõe, como diz Stein (1983), a ser somente um método científico, senão, uma proposta filosófica e epistemológica de ver o mundo a ser pesquisado, e, ao mesmo tempo, de repensar a própria postura do pesquisador como sujeito presente, influente e influenciável pela realidade social. Desta maneira, complementa-se o movimento hermenêutico - que valoriza a linguagem do ser humano que se considera livre e é importante elemento de construção social - por intermédio de um segundo movimento dialético - que questiona a liberdade e as condicionantes daquela linguagem, num processo circular que engloba não somente o objeto cognoscível, mas, sobretudo, o pesquisador cognoscente.

Quanto ao caso específico das ciências sociais, notadamente, do estudo de um fenômeno complexo $e$ hostil como o tráfico de drogas, o método propicia uma aproximação da literatura (coordenada por questões históricas e espaciais), bem como, uma atividade de comparação de saberes, que propiciam uma análise mais madura do tema, e, sobretudo, uma autocrítica em torno dos saberes do próprio pesquisador. Quanto a este segundo ponto, talvez, se mostre a mais significativa contribuição do método, já que o debate em torno do tráfico de drogas se encontra, como mencionado, impregnado de preconceitos e perturbações sistêmicas em relação ao discurso oficial, que, certamente, impregnam o pesquisador que, antes de mais nada, é cidadão e detentor de um saber que inicia do senso comum.

Igualmente, há uma complexidade linguística e semiótica inquestionável nos vários âmbitos em que o fenômeno é trabalhado, de modo a tornar necessário que o pesquisador, para além de seus saberes, respeite e considere o saber alheio, para uma aproximação real. Assim, embora o método seja um objeto de livreescolha, de outro lado, é notório concluir que caberá ao pesquisador se apegar à procedimentos complexos para uma análise compromissada de objetos complexos, de modo que a opção (e emprego responsável) das técnicas propugnadas pelo método hermenêutico e dialético, por seu caráter naturalmente eclético (ou, se preferir, democrático) e a exigência de uma visão compromissada com o saber externo ao pesquisador, certamente, pode representar um importante contributo à ciência social. 


\section{Considerações finais}

Como visto nas seções precedentes, a complexidade dos objetos de estudo das ciências sociais impõe a utilização de métodos (convencionais ou não) cada vez mais pluralistas e interdisciplinares, justamente, para que se ocasione o avanço da própria ciência através da superação de hipóteses ad hoc, improvisadas, que apenas imobilizam saberes em detrimento do desenvolvimento da sociedade (FEYERABEND, 2011). Sob este intento, a hermenêutica-dialética surgiu como um método que se propôs ao estudo da linguagem, veículo e limite de qualquer processo de manifestação, construção ou apreensão do conhecimento, sem, no entanto, olvidar suas condicionantes e determinantes no contexto espacial e histórico.

E, principalmente, pressupôs uma triangulação de teorias e dados capaz de promover uma reanálise dos achados (movimento de negação), diante de outros pesquisadores sobre o assunto, ou, ainda, diante de teorias e resultados de outros estudos, justamente, para confrontação das conclusões e revelação de realidades ocultadas pela comunicação sistematicamente perturbada. Com isso, o método apregoou não só uma rediscussão dos postulados de um estudo em desenvolvimento, mas, principalmente, da postura do próprio pesquisador e suas convicções.

Obviamente, ele impende de uma utilização ética e madura, tal qual ocorre com todos os demais métodos existentes (convencionais ou não), sob pena de apenas reproduzir conhecimentos consolidados e, talvez, concernentes a programas de alienação social. É por isso que, também, se deve ter em mente que a proposta transdisciplinar, conforme informa Minayo (1994) não deve ser tomada como uma panaceia para os males científicos atuais, já que depende de disposição e coerência para restabelecer um importante mecanismo que parece ter sido desvalorizado ao longo do desenvolvimento das diversas ciências (talvez, de forma intencional): o diálogo e o objetivo de retorno do conhecimento ao meio social, em benefício da própria humanidade (ALVES, 2013)1.

\section{Referências}

ALENCAR, Tatiane de Oliveira Silva; NASCIMENTO, Maria Ângela Alves do; ALENCAR, Bruno Rodrigues. Hermenêutica Dialética: uma experiência enquanto método de análise na pesquisa sobre o acesso do usuário à assistência farmacêutica. Revista Brasileira de Promoção da Saúde, [s. I.], v. 25, n. 2, p. 243-250, 2012. https://doi.org/10.5020/18061230. 2012.p243

ALVES, Rubens. Filosofia da Ciência: introdução ao jogo e suas regras. 18. ed. São Paulo: Edições Loyola, 2013.

AMORIM, Carlos. Comando Vermelho: a história do crime organizado. 1. ed. Rio de Janeiro: BestBolso, 2011.

AMORIM, Carlos. CV-PCC: A Irmandade do Crime. 13. ed. Rio de Janeiro: Record, 2013.

ANITUA, Gabriel Ignacio. História dos Pensamentos Criminológicos. 1. ed. Rio de Janeiro: Revan, 2015.

ARAÚJO, Tarso. Almanaque das Drogas. 1. ed. São Paulo: Leya, 2012.

BAUMAN, Zygmunt. O Mal-estar da Pós-modernidade. 1. ed. Rio de Janeiro: Zahar, 1998.

BICALHO, Lucinéa Maria; OLIVEIRA, Marlene. Aspectos Conceituais da Multidisciplinaridade e da Interdisciplinaridade e a Pesquisa em Ciência da Informação. Encontros Bibli: Revista Eletrônica de Biblioteconomia e Ciência da Informação, [s. I.], v. 16, n. 32, p. 1-26, 2011. https://doi.org/10.5007/1518-2924.2011v16n32p1

BORTOLOZZI, Remom Matheus. O sentido do trabalho para jovens trabalhadores da economia da droga: exame retrospectivo. 2014. Dissertação (Mestrado) - Programa de Pós-graduação em Educação da Universidade de Brasília, Brasília, 2014. https://doi.org/10.26512/2014.10.d.17661

CARVALHO, Salo de. A política Criminal de Drogas no Brasil: Estudo Criminológico e Dogmático da Lei 11.343/06. 8. ed. São Paulo: Saraiva, 2016. 
D’ELIA FILHO, Orlando Zaccone. Acionistas do nada: Quem são os traficantes de Drogas. 1. ed. Rio de Janeiro: Revan, 2014.

FROMM, Deborah. Deus e o Diabo na Terra do Crack: uma etnografia da "cosmopolítica" batista. Monografia.

Universidade Federal de São Carlos (UFSCar). 2014.

FEYERABEND, Paul. Contra o método. 2. ed. São Paulo: Unesp, 2011.

GARCIA, Eduardo da Silva. Sujeitos Responsáveis: Notas etnográficas sobre o consumo de drogas entre jovens paulistanos de classe média. In: VI ENCONTRO NACIONAL DE ESTUDOS DO CONSUMO E II ENCONTRO LUSO-BRASILEIRO DE ESTUDOS DO CONSUMO. Vida sustentável: práticas cotidianas de consumo. 2012, [s. I.]. Anais [...]. [S.I.: s. n.]: 2012. https://doi. org/10.5151/engpro-eneeamb2016-gap-007-4985

GOMES, Romeu; SOUZA, Edinilsa Ramos de; MINAYO, Maria Cecília de Souza; MALAQUIAS, Juaci Vitória; SILVA, Cláudio Felipe Ribeiro da. Organização, Processamento, Análise e Interpretação de dados: o desafio da triangulação. In: MINAYO, Maria Cecília de Souza; ASSIS, Simone Gonçalves de; SOUZA, Edinilsa Ramos de. Avaliação por Triangulação de Métodos: abordagem de programas sociais. 20. ed. Rio de Janeiro: Editora Fiocruz, 2005. https://doi.org/10.7476/9788575415474

HABERMAS, Jürgen. Dialética e Hermenêutica: para a crítica da Hermenêutica de Gadamer. Porto Alegre: LP\&M, 1987.

MARQUES, Adalton. Crime e Proceder: Um experimento antropológico. 1. ed. São Paulo: Alameda, 2014.

MARTINS, Gilberto de Andrade; THEÓPHILO, Carlos Renato. Metodologia da Investigação Científica Aplicada às Ciências Sociais Aplicadas. 3. ed. São Paulo: Atlas, 2016.

MATALLO JR. Heitor. A problemática do Conhecimento. In: CARVALHO, Maria Cecília Maringoni (org.). Construindo o Saber: Metodologia Científica. 24. ed. Campinas: Papirus, 2012.

MEZZAROBA, Orides; MONTEIROS, Cláudia Servilha. Manual de Metodologia da Pesquisa no Direito. 6. ed. São Paulo: Saraiva, 2014.

MINAYO, Maria Cecília de Souza. Hermenêutica-Dialética como Caminho do Pensamento Social. In: MINAYO, Maria Cecília de Souza. Caminhos do Pensamento: epistemologia e método. 1 ed. Rio de Janeiro: Editora Fiocruz, 2002. https://doi. org/10.7476/9788575414118

MINAYO, Maria Cecília de Souza. Interdisciplinaridade: Funcionalidade ou Utopia? Revista Saúde e Sociedade, [s. I.], v. 3, n. 2, p. 42-64. 1994. https://doi.org/10.1590/s0104-12901994000200004

MINAYO, Maria Cecília de Souza. Introdução: conceito de avaliação por triangulação de Métodos. In: MINAYO, Maria Cecília de Souza; ASSIS, Simone Gonçalves de; SOUZA, Edinilsa Ramos de. Avaliação por Triangulação de Métodos: abordagem de programas sociais. 20. ed. Rio de Janeiro: Editora Fiocruz, 2005. https://doi.org/10.7476/9788575415474

MORAIS, João Francisco Regis de. Ciência e Perspectivas Antropológicas Hoje. In: CARVALHO, Maria Cecília Maringoni (org.). Construindo o Saber: Metodologia Científica. 24. ed. Campinas: Papirus, 2012.

OLSEN, Wendey. Coleta de Dados: Debates e Métodos Fundamentais em Pesquisa Social. 1. ed. Porto Alegre: Penso, 2015.

PICANÇO, Felícia Silva; LOPES, Natânia Pinheiro de Oliveira. O tráfico de drogas em formas: notas de pesquisas sobre o Rio de Janeiro. Análise Social, [s. I.], v. 218, n. 1, p. 96-120, 2016.

REIS NETTO, Roberto Magno; CHAGAS, Clay Anderson Nunes. A associação externa como forma de integração dos presídios às redes externas do tráfico: a percepção dos agentes territoriais da segurança pública no Estado do Pará. Estudos geográficos, [s. I.], v. 16, n. 02, p. 176-193, 2018a. https://doi.org/10.5016/estgeo.v16i2.12994

REIS NETTO, Roberto Magno; CHAGAS, Clay Anderson Nunes. Estratégias e mediatos utilizados pelo tráfico de drogas para integração dos presídios às redes territoriais externas: uma revisão da literatura. Revista Opinião Jurídica, [s. I.], v. 16, n. 23. p. 110-139. 2018b. https://doi.org/10.12662/2447-6641oj.v16i23.p110-139.2018

ROCHA, Andréa Pires. Estudo de Fenômenos Vinculados ao Tráfico de Drogas: Caminhos Metodológicos Percorridos. Textos \& Contextos, Porto Alegre, v. 9, n. 1, p. 103-117, 2010.

RODRIGUES, Thiago. Política e Drogas nas Américas. 1. ed. São Paulo: EDUC/FAPESP, 2004. 
SAVIANO, Roberto. Zero, Zero, Zero. 1. ed. São Paulo: Companhia das Letras, 2014.

SILVA, Érika Barbosa de Oliveira; PEREIRA, Adriana Lenho de Figueiredo; PENNA, Lúcia Helena Garcia. Estereótipos de gênero no cuidado psicossocial das usuárias de cocaína e crack. Cad. Saúde Pública, [s. I.], v. 34, n. 5, p. 1-10, 2018. https://doi.org/10.1590/0102-311x00110317

SOMEKH, Bridget; BURMAN, Erica; DELAMONT, Sara; MEYER, Julienne; MALCOM, Payne; THORPE, Richard. Pesquisa nas Ciências Sociais. In: SOMEKH, Bridget; Lewin, Cat. Teoria e Métodos de Pesquisa Social. Petrópolis: Editora Vozes, 2015.

STEIN, Ernildo. Dialética e Hermenêutica: Uma controvérsia sobre o método em filosofia. Síntese, [s. I.], v. 1, n. 29, p. 21-48, 1983.

UNITED NATIONS OFFICE ON DRUGS AND CRIME. UNODC/ONU. World Drug Report 2015. New York: ONU, 2015.

ZALUAR, Alba. Integração Perversa: Pobreza e Tráfico de Drogas. 1. ed. Rio de Janeiro: Editora FGV, 2004.

ZALUAR, Alba. Violência x Pobreza x Criminalidade x Migração. Cadernos de Saúde Pública, Rio de Janeiro, v. 10, n. 1. p. 213-217, 1994. https://doi.org/10.1590/S0102-311X1994000500016

\section{Nota}

\footnotetext{
${ }^{1}$ Inclusive, em respeito ao mencionado diálogo, cumpre registrar o agradecimento pelo apoio material (por meio de textos e livros disponibilizados) e científico (por meio de debates, sugestões e discussões) fornecido aos autores, pelos grupos de pesquisa a seguir: a) Érgane - Instituto Científico da Amazônia; b) Laboratório de Pesquisa em Geografia da Violência e do Crime (Lab-Geovcrim - UEPA/PA); c) Observatório de Estudos de Defesa da Amazônia (OBED/NAEA/UFPA); e, d) Grupo de Pesquisa em Métodos de Diagnóstico em Segurança Pública (PPGSP/UFPA). Toda ciência é fruto histórico do espírito de cooperação de quem deseja entender e realidade.
}

Recebido em: 20/11/2019.

Aprovado em: 03/12/2019.

Publicado em: 30/01/2020

\section{Correspondência para:}

Universidade Federal do Pará (UFPA)

Instituto de Filosofia e Ciências Humanas (IFCH)

Av Perimetral, 2651 - Campus Básico, Bairro Guamá

66077-830, Belém, PA, Brasil

\section{Autores:}

Roberto Magno Reis Neto

Doutorando pelo programa de Pós-Graduação em Geografia (UFPA). Mestre no Programa de Pós-Graduação em Segurança Pública da Universidade Federal do Pará. Pós-Graduado em Direito Processual Civil (UGF/DF). Pesquisador (Laboratório de Pesquisa em Geografia da Violência e do Crime/UEPA), Observatório Anánkê - ESMAC/PA e do Grupo de Métodos em Diagnóstico em Segurança Pública - PPGSP/UFPA. Graduado em Direito (UFPA). Oficial de Justiça. Avaliador do Tribunal de Justiça do Estado do Pará.

Orcid: http://orcid.org/0000-0002-5076-6149

E-mail: bob_reis_ufpa@yahoo.com.br

Clay ANDERSON Nunes Chagas

Doutor em Desenvolvimento Socioambiental pelo Núcleo de Altos Estudos Amazônicos da Universidade Federal do Pará (UFPA). Professor do Programa de Pós-graduação em Geografia e no Programa de Pós-graduação em Segurança Pública da Universidade Federal do Pará (UFPA). Professor colaborador do Programa do Pós-graduação da Universidade de Cabo Verde. Líder do Laboratório de Pesquisa em Geografia da Violência e do Crime/UEPA. Vice-reitor da Universidade do Estado do Pará. Orcid: http://orcid.org/0000-0002-4223-0192

E-mail: claychagas@yahoo.com.br 